\title{
Aortic dimensions as predictors of adverse events
}

Leonard N. Girardi, MD, Christopher Lau, MD, and Ivancarmine Gambardella, MD

There is an accumulating body of evidence suggesting that relying on a single measurement, aortic diameter, may be too restrictive when advising patients on the need for ascending aneurysm repair. As outcomes for procedures like composite valve-graft ${ }^{1}$ and valve-sparing root replacement ${ }^{2}$ continue to improve, it is crucial to scrutinize current guidelines for opportunities to offer these increasingly safe and durable operations to patients at risk for adverse aortic events (AAEs). Aortic diameter indexed for either body surface area (BSA) or height may prove to be more accurate than diameter alone in predicting aortic rupture, aortic dissection, or sudden death. However, the most common approach, upon which most recommendations are based, relies on aortic diameter/ radius and wall tension, as predicted by LaPlace's law, ${ }^{3}$ to determine the need for surgery. Aortic length has recently garnished attention as another parameter worthy of analysis. We examine the support for using length as a predictor of AAE and contrast this to contemporary data upon which current guidelines base recommendations for repair of ascending aortic aneurysms.

\section{WHY DID WE INITIALLY ADOPT AORTIC DIAMETER?}

Surgeons use aortic diameter as the main measurement to recommend intervention for aortic aneurysms primarily because it is the only metric consistently referenced in guidelines from both cardiothoracic and vascular surgery societies. Although the recommendations in these guidelines are regarded as either Class I (benefit $>>>$ risk, procedure/treatment SHOULD be performed) or Class IIa (benefit $>>$ risk, additional studies with focused objectives needed, IT IS REASONABLE to perform procedure), the Level of Evidence supporting these recommendations is "C," arising from expert consensus, case studies, or "standard of care." Irrespective of whether the recommendations arise from North American or European guidelines, the level of evidence supporting diameter is substantially stronger for the abdominal aorta compared with its thoracic counterpart. For abdominal aneurysms, Class I, Level of

\footnotetext{
From the Department of Cardiothoracic Surgery, Weill Cornell Medicine, New York, NY.

Received for publication April 6, 2020; revisions received June 16, 2020; accepted for publication June 22, 2020; available ahead of print July 16, 2020.

Address for reprints: Leonard N. Girardi, MD, Department of Cardiothoracic Surgery, 525 East 68th St, M-404, New York, NY 10065 (E-mail: lngirard@med.cornell. edu).

J Thorac Cardiovasc Surg 2021;161:1193-7

$0022-5223 / \$ 36.00$

Copyright (C) 2020 by The American Association for Thoracic Surgery

https://doi.org/10.1016/j.jtcvs.2020.06.137
}

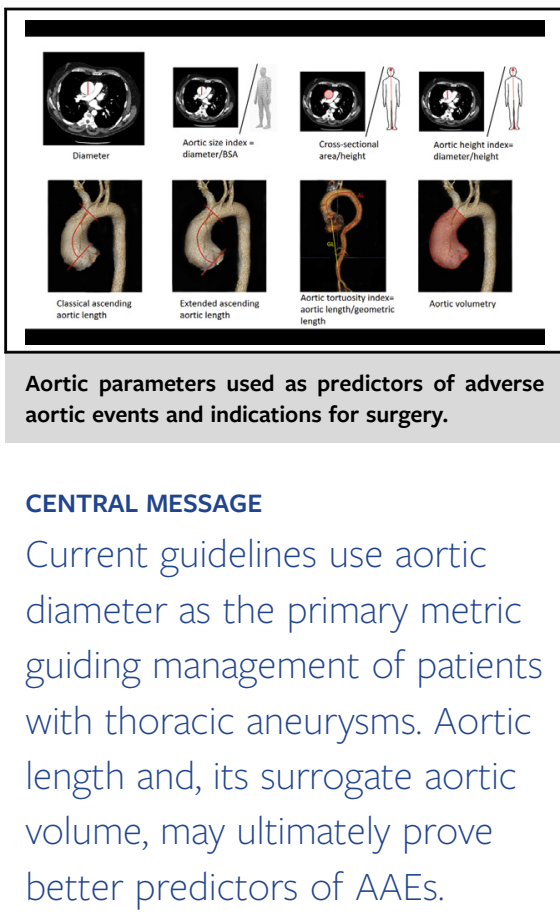

This Invited Expert Opinion provides a perspec tive on the following paper: J Am Coll Cardiol 2019 Oct 15;74(15):1883-1894. https://doi.org/10 1016/j.jacc.2019.07.078.

See Commentaries on pages 1198 and 1202.

Evidence A exists supporting: (1) at diameters $\geq 5.5 \mathrm{~cm}$ the risk of rupture outweighs the risk of open repair (UKSTAT and Aneurysm Detection and Management Veterans Affairs Cooperative Study [ADAM] trials ${ }^{4,5}$ ); and (2) endovascular repair does not offer an advantage over surveillance for smaller aneurysms 4 to $5.5 \mathrm{~cm}$ (Comparison of surveillance versus Aortic Endografting for Small Aneurysm Repair study [CESAR $]^{6}$ and Positive Impact of Endovascular Options for Treating Aneurysms Early [PIVOTAL] trials ${ }^{7}$ ).

Because there are no clinical trials evaluating treatment efficacy for the thoracic aorta, the argument for diameter begins with an understanding of the normal distribution for each aortic segment. One of the earliest reports of normal ascending aortic diameter was published in $1991 .^{8}$ With improvements in computed tomography (CT) imaging and echocardiography and an acknowledgment of the influence of age, sex, and body size indices on aortic diameter, "normals" for the ascending aorta and aortic root were established. ${ }^{9,10}$ The mean normal diameters of the tubular 
ascending aorta for female and male patients were $2.7 \mathrm{~cm}$ and $3.6 \mathrm{~cm}$, respectively. The normal diameters in the sinuses of Valsalva were somewhat larger for women and men at $3.0 \mathrm{~cm}$ and $3.9 \mathrm{~cm}$, respectively.

Using these baseline dimensions, investigators began to quantify the dimensions at which AAE occur with greater frequency. ${ }^{11}$ A turning point for aortic diameter occurred after the seminal paper from the Yale group demonstrated a significant increase, a "hinge point," in the incidence of AAE once the ascending aorta became $>6.0 \mathrm{~cm} .{ }^{12}$ Using logistic regression analysis on measurements and AAEs recorded from 230 patients with thoracic aneurysms, they demonstrated a significant increase in the number of AAE at this diameter. To reduce the incidence of potentially fatal complications, they opined that a diameter of $5.5 \mathrm{~cm}$ should become the trigger for surgical intervention. Since then, based on this single, relatively small study, $5.5 \mathrm{~cm}$ became the benchmark diameter upon which guidelines were created.

The "aortic size paradox," however, recognizes the flaws in establishing a single diameter as a benchmark. Pape and colleagues ${ }^{13}$ examined data from 591 patients with acute type A dissections (ATAD) enrolled in The International Registry for Aortic Dissection. The mean ascending aortic diameter in those with ATAD was $5.3 \mathrm{~cm}$. Nearly $60 \%$ occurred in patients with diameters less than $5.5 \mathrm{~cm}$ and $40 \%$ of patients dissected with diameters less than $5.0 \mathrm{~cm}$. The ascending aorta expands between $16.9 \%$ and $31.9 \%$ upon dissection, suggesting that the International Registry for Aortic Dissection data significantly overestimated the actual ascending diameter before the dissection event. ${ }^{14}$ Clearly there was room for improvement. To explain this apparent paradox, the Yale group analyzed ascending aortic diameter in a "normal" population of 3573 patients undergoing screening magnetic resonance imaging in the Multi-Ethnic Study of Atherosclerosis (MESA). ${ }^{15}$ They found an 89-fold increase in risk of dissection in patients with aorta 4.0 to $4.4 \mathrm{~cm}$ and a 346-fold increase when aortic diameter was greater than $4.5 \mathrm{~cm}$. Another "hinge point" was the interpretation with an accompanying call for intervention when aortas exceeded this fairly common diameter. Unfortunately, aortic root diameter was not measured in this study, a significant flaw in underestimating the largest diameter of aorta at risk. An update of the Yale database expanding it to 3349 patients allowed for a more granular analysis of aortic diameter. ${ }^{16}$ They found that there are actually 2 hinge-points, one at $5.75 \mathrm{~cm}$ as previously shown and another at $5.25 \mathrm{~cm}$. This prompted an examination of whether surgeons should move the intervention criterion "leftward," toward a smaller aortic diameter to avoid more AAE. However, these data do imply a need for more refined analysis and justifies a closer look at diameter indexed for various patient characteristics.

\section{INDEXING AORTIC SIZE}

While the physics of aortic wall tension support the use of aortic diameter as a reliable metric to base decisions for prophylactic surgery, the concept of "one size fits all" has fallen out of favor among surgeons. Indexing aortic diameter to BSA, the aortic size index (ASI) was proposed in $2006 .{ }^{17}$ In 410 patients, an ASI $<2.75 \mathrm{~cm} / \mathrm{m}^{2}$ was deemed low risk for AAEs whereas those above $4.25 \mathrm{~cm} / \mathrm{m}^{2}$ were felt to be in need of surgery. A closer examination of these data reveals limitations of this form of indexing. A patient with a $6.5-\mathrm{cm}$ ascending aneurysm and BSA of 2.40 would be considered low risk by ASI. Surgery would not be recommended. Similarly, in someone with a BSA of 1.90 , would anyone consider an $8.0-\mathrm{cm}$ aorta "moderate" risk and recommend against intervention? Critics rightfully pointed out that BSA/weight is variable throughout life and is heavily influenced by factors that should not change the physiology of the aorta within. More reliable indices were clearly necessary.

Around this time, aortic cross-sectional area to height ratio was proposed as a superior method to ascribe risk for AAE in patients with genetically triggered aortopathy. ${ }^{18,19}$ However, this index shares limitations of the other indices due to the basic diameter-based calculation of cross-sectional area. A larger series examining this ratio in 771 patients with trileaflet aortic valves demonstrated that patients with an aortic area/height ratio $>10 \mathrm{~cm}^{2} / \mathrm{m}$ had a significantly reduced long-term survival. ${ }^{20}$ However, the use of all-cause mortality rather than AAE as an end point limited widespread acceptance of this interesting metric. Its use is still a class IIa, level of evidence $\mathrm{C}$ recommendation only potentially applicable to those with genetically triggered aneurysms or bicuspid aortopathy. Aortic height index (AHI) was also examined. Surgery was recommended when the AHI exceeded $3.21 \mathrm{~cm} /$ $\mathrm{m} .{ }^{16}$ However, complex statistical analysis failed to demonstrate a significant improvement in predicting AAE when comparing AHI with ASI (concordance index ASI, 0.617 vs AHI, 0.645). Therefore, AHI never gained widespread clinical use as a marker for aortic intervention, especially in patients without connective tissue disorders.

\section{WHAT ABOUT AORTIC LENGTH?}

To have a cogent discussion on the utility of ascending aortic length (AAL) as a predictor of AAE, one needs to understand the nomenclature and normal values for this variable. The anatomic landmarks used to measure AAL are somewhat heterogeneous but easily calculated. Classical AAL (c-AAL) is the distance between the sinotubular junction and brachiocephalic trunk. Its mean value is $7.10 \pm 2.80 \mathrm{~cm}$ on a centerline coronal plane, and $6.72 \pm 1.70 \mathrm{~cm}$ on the sagittal plane. However, when the sinotubular junction is effaced, commonly seen with aneurysms involving both the sinuses of Valsalva and the tubular ascending aorta, consistent measurements are challenging. 
To overcome this, some prefer extended AAL (e-AAL), which represents the distance between the aortic annulus and the base of the innominate artery. This more consistently calculated length resulted in a mean e-AAL of $11.2 \pm 1.3 \mathrm{~cm}$ on the reconstructed flattened aorta. ${ }^{21,22}$

Aortic length increases with age regardless of BSA. In a cohort of 220 patients followed with centerline CT measurements, from age 20 to 80 years, the mean length of the thoracic aorta increased by $66 \mathrm{~mm}$ in female and $59 \mathrm{~mm}$ in male patients. There was a difference in percentage increase among aortic segments: ascending aorta $142 \%$, aortic arch $169 \%$, and proximal descending aorta $247 \%{ }^{23}$ The configuration of the aorta also evolves as a consequence of age-related lengthening. The aortic apex migrates distally from the origin of the great vessels in young age (type I aorta), to a point distal to the left subclavian artery in elderly patients (type II aorta). Increasing aortic tortuosity becomes the geometrical byproduct of aortic elongation that is not matched by somatic growth as the vertebral column length decreases over time. ${ }^{24}$ Tortuosity can be quantified by the aortic tortuosity index (ATI), the ratio of the centerline to the straight linear distance between 2 endoluminal points. On average, ATI increases from 1.07 (age 20 years) to 1.21 (age 80 years). ${ }^{23,25}$

An early examination of the correlation between AAL and AAEs was published by Krüger and colleagues. ${ }^{26}$ They demonstrated that c-AAL was increased in patients with ATAD compared with healthy controls $(108 \mathrm{~mm}$ vs $84 \mathrm{~mm}$, $P>.001)$. A risk-adjusted corroboration of this was provided by Heuts and colleagues ${ }^{27}$ who, after propensity matching, found c-AAL significantly longer in patients with ATAD compared with controls $(78.6 \pm 8.8 \mathrm{~mm}$ vs $68.9 \pm 7.2 \mathrm{~mm}$, $P<.001)$. Interestingly, c-AAL independently predicted ATAD on multivariable regression analysis. ${ }^{27}$

As previously done for aortic diameter, the Yale group identified thresholds for intervention based on AAL. They demonstrated that e-AAL $\geq 13 \mathrm{~cm}$ was associated with a nearly 5 -fold greater yearly rate of AAEs compared with an e-AAL $<9 \mathrm{~cm}$. On multivariable regression, the odds of AAEs were 12.4 times greater with an e-AAL $\geq 13 \mathrm{~cm}$ versus $<9 \mathrm{~cm}$. Two hinge points of e-AAL corresponded to significant increase in the AAE rate: 11.5 to $12.0 \mathrm{~cm}$ and 12.5 to $13 \mathrm{~cm}$. Hence, they suggested that an e-AAL $\geq 11 \mathrm{~cm}$ become a threshold for intervention. ${ }^{22}$

Surrogates of increased aortic length (ie, high ATI and a type II aorta) have also been related to a greater rate of AAEs, before and after aortic intervention. In a Marfan cohort followed for 4 years, patients who developed dissection or underwent surgery had a greater ATI at baseline. ${ }^{28}$ An ATI $>1.95$ was linked to a 13 -fold greater probability of dissection or surgery compared with an ATI $<1.95$. Independent predictors for the combined end point of dissection or surgery were ATI (hazard ratio [HR], 12.8; $P=.030$ ) and aortic root diameter (HR, $1.451 ; P<.001)$. ATI was the only predictor for aortic dissection (HR, 12.083; $P=.039)$. Chen and colleagues ${ }^{29}$ dichotomized their cohort of patients undergoing thoracic endovascular aneurysm repair in high versus low ATI groups. The high ATI group had an increased rate of endoleaks (odds ratio, 9.95; 95\% confidence interval, 2.06-48) and lower 5-year survival (63\% vs $86 \%, P=.023) .{ }^{29}$ Krüger and colleagues evaluated the prevalence of conformational variants of the aortic arch not only in patients with frank aneurysm (diameter $>5.5 \mathrm{~cm}$ ) or ATAD, but also in individuals "at risk" because of aortic ectasia (diameter $4.5-5.4 \mathrm{~cm}$ ) or pre-ATAD (ie, patients scanned in the 24 months before ATAD occurred). A type II aorta was much less frequent in the control group $(22.7 \%)$ than in the pathologic groups: $45.1 \%$ of ectasia group, $60.5 \%$ of aneurysm group, $58.8 \%$ of pre-ATAD group, and $45.2 \%$ of ATAD group $(P<.001){ }^{26}$

Finally, aortic length may ultimately be more reliable than either diameter or cross-sectional area when trying to estimate aortic dimensions before ATAD. In a limited subset of 10 patients who had CT scans within 1.5 years of a dissection, AAL increased only $2.7 \%$, a substantially smaller percentage change when compared to diameter measured in the same setting. ${ }^{22}$

\section{TWO IS BETTER THAN ONE? AORTIC VOLUME}

Since aortic diameter and length have reasonable predictive value for AAEs, would a metric combining the 2 provide greater sensitivity? Aortic volumetry (volume $=\pi$ [diameter $/ 2]^{2} \times$ length) provides a quantitative measurement that may be useful for both preoperative surveillance and postoperative follow-up. The absolute values seen with aortic volume are significantly larger than corresponding diameters. For a $60 \mathrm{~mm}$-long aneurysm, a barely detectable $1 \mathrm{~mm}$ expansion in diameter corresponds to a $10-\mathrm{mL}$ increase in aortic volume. ${ }^{30}$ The possibility for increased sensitivity seems obvious.

During surveillance of infrarenal abdominal aneurysms, reliance on diameter alone missed $14 \%$ to $42 \%$ of significant changes detected by volumetry. ${ }^{30,31}$ Similar findings for the thoracic aorta were reported by Trinh and colleagues, ${ }^{32}$ who demonstrated that the percentage growth of volume measurement was 3.7 greater than diameter growth of the ascending aorta in patients with bicuspid aortopathy. After thoracic endovascular aneurysm repair (EVAR), a $>10 \%$ volume increase also had a greater sensitivity than a $>5$ $\mathrm{mm}$ diameter increase in predicting type I endoleak. ${ }^{33}$ Finally, in those with type II endoleak after EVAR, diameter missed $63 \%$ of significant changes detected by volumetry. Although further investigation is necessary before aortic volume is confirmed useful for aortic surveillance, it may prove to be more applicable as a harbinger of AAEs following thoracic EVAR and EVAR. This could be particularly useful when following type II endoleaks, where consensus is lacking on the timing/need for reintervention. ${ }^{34}$ 


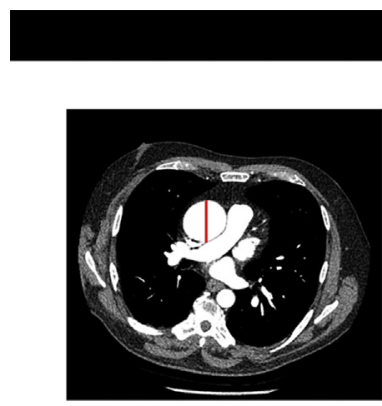

Diameter

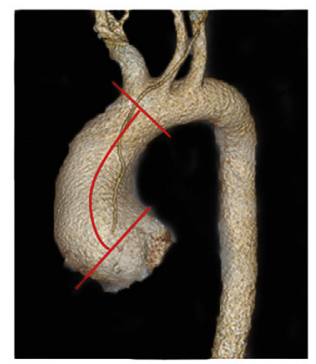

Classical ascending aortic length



Aortic size index = diameter/BSA

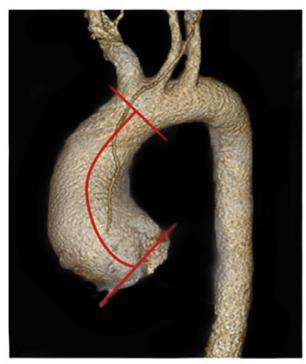

Extended ascending aortic length



Cross-sectional area/height

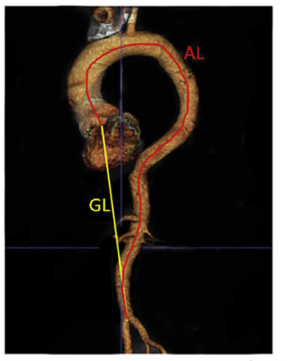

Aortic tortuosity index= aortic length/geometric length



Aortic height index= diameter/height



Aortic volumetry



FIGURE 1. Measurement of aortic parameters and indices on cross-sectional and 3-dimensional imaging. BSA, Body surface area.

It should be noted that additional investigations combine indexed metrics, such as aortic length/height index, aortic diameter/height index. ${ }^{22}$ Further investigation is needed to

TABLE 1. Aortic measurements and indices with recommended thresholds for surgical intervention

\begin{tabular}{|c|c|c|}
\hline Parameter & Calculation & $\begin{array}{c}\text { Recommended } \\
\text { threshold for surgical } \\
\text { intervention (without } \\
\text { aortopathy) }\end{array}$ \\
\hline Diameter & Diameter & $5.5 \mathrm{~cm}$ \\
\hline Aortic size index & $\begin{array}{l}\text { Diameter/body surface } \\
\text { area }\end{array}$ & $>2.75 \mathrm{~cm} / \mathrm{m}^{2}$ \\
\hline $\begin{array}{l}\text { Cross-sectional } \\
\text { area index }\end{array}$ & $\begin{array}{l}\text { Cross-sectional area/ } \\
\text { height }\end{array}$ & $>10 \mathrm{~cm}^{2} / \mathrm{m}$ \\
\hline $\begin{array}{l}\text { Aortic height } \\
\text { index }\end{array}$ & Diameter/height & $\begin{array}{l}\text { High risk } \\
\quad>3.21 \mathrm{~cm} / \mathrm{m} \\
\text { Severe risk } \\
>4.06 \mathrm{~cm} / \mathrm{m}\end{array}$ \\
\hline $\begin{array}{l}\text { Classical } \\
\text { ascending aortic } \\
\text { length }\end{array}$ & $\begin{array}{l}\text { Length (sinotubular } \\
\text { junction to innominate } \\
\text { origin) }\end{array}$ & - \\
\hline $\begin{array}{l}\text { Extended } \\
\text { ascending aortic } \\
\text { length }\end{array}$ & $\begin{array}{l}\text { Length (aortic annulus to } \\
\text { innominate origin) }\end{array}$ & $>11 \mathrm{~cm}$ \\
\hline $\begin{array}{l}\text { Aortic tortuosity } \\
\text { index }\end{array}$ & $\begin{array}{l}\text { Centerline distance/linear } \\
\text { distance }\end{array}$ & - \\
\hline Aortic volumetry & $\pi[\text { diameter } / 2]^{2} \times$ length & - \\
\hline
\end{tabular}

validate these complex calculations as meaningful predictors of AAEs (Figure 1).

\section{CONCLUSIONS}

For the aneurysmal ascending aorta, aortic diameter remains the measurement upon which guidelines have been created for aortic surveillance and intervention. Despite the indisputable correlation between aortic diameter and wall tension, it is obvious that the predictive value of a single metric may be insufficient. A significant subset of patients with diameters below surgical thresholds continue to experience life-threatening AAEs. Clearly, there is much room for improvement (Table 1).

Currently, aortic cross-sectional area to height ratio remains the only indexed metric included in guidelines for thoracic aortic disease. Specifically, it is recommended only for the care of patients with genetically triggered aneurysms. Unfortunately, the complexity of calculating this index negates more widespread investigation and application. Aortic length, or a combined metric using length, such as aortic volume, is consistently measured with currently available CT and magnetic resonance imaging software. In the limited investigations of both aortic length and volume, there are potential opportunities to increase the sensitivity of predicting AAEs in those with smaller aortic diameters. Further evidence corroborating the predictive value of aortic indices incorporating length or volume for 
AAE will be necessary before experts in the field can consider incorporating these measurements into the existing guidelines. While indices incorporating measurements of the body around the aorta may have limitations, perhaps indices specific to the physics of the aorta itself, such as those derived from 4-dimensional flow magnetic resonance imaging will be more reliable predictors of AAE. In addition, greater predictability of need for reintervention following endovascular repair may prove to be a valuable byproduct of efforts to improve thoracic aortic surveillance. Given the dramatic improvements in outcomes for patients undergoing complex ascending and aortic root aneurysm repair, further investigation is justified to increase our ability to identify patients who may benefit from surgery despite aortic diameters below traditional thresholds.

\section{Conflict of Interest Statement}

The authors reported no conflicts of interest.

The Journal policy requires editors and reviewers to disclose conflicts of interest and to decline handling or reviewing manuscripts for which they may have a conflict of interest. The editors and reviewers of this article have no conflicts of interest.

\section{References}

1. Gaudino M, Weltert L, Munjal M, Lau C, Elsayed M, Salica A, et al. Early clinical outcome after aortic root replacement using a biological composite valved graft with and without neo-sinuses. Eur J Cardiothorac Surg. 2017;51:316-21.

2. Gaudino M, Lau C, Munjal M, Avgerinos D, Girardi LN. Contemporary outcomes of surgery for aortic root aneurysms: a propensity-matched comparison of valve-sparing and composite valve graft replacement. J Thorac Cardiovasc Surg. 2015; 150:1120-229.

3. Li JK. Comparative cardiac mechanics: Laplace's law. J Theoret Biol. 1986;118: 339-43.

4. Powel JT, Brady AR, Brown LC, Forbes, Fowkes FGR, Greenhalgh RM, et al. Mortality results for randomized controlled trial of early elective surgery or ultrasonographic surveillance for small abdominal aortic aneurysms. The UK small aneurysm trial participants. Lancet. 1998;352:1649-55.

5. Lederle FA, Wilson SE, Johnson GR, Reinke DB, Littooy FN, Acher CW, et al. Immediate repair compared with surveillance of small abdominal aortic aneurysms. N Engl J Med. 2002;346:1437-44.

6. Cao P, De Rango P, Verzini F, Parlani G, Romano L, Cieri E, et al. Comparison of surveillance versus aortic endografting for small aneurysm repair (CAESAR): results from a randomized trial. Eur J Endovasc Surg. 2011;41:13-25.

7. Ouriel K, Clair DG, Kent KC, Zarins CK, Positive Impact of Endovascular Options for Treating Aneurysms Early (PIVOTAL) Investigators. Endovascular repair compared with surveillance for patients with small abdominal aortic aneurysms. J Vasc Surg. 2010;51:1081-7.

8. Johnston KW, Rutherford RB, Tilson MD, Shah DM, Hollier L, Stanley JC. Suggested standards for reporting on arterial aneurysms. Subcommittee on reporting standards for arterial aneurysms, ad hoc committee on reporting standards, Society for Vascular Surgery and North American Chapter, International Society for Cardiovascular Surgery. J Vasc Surg. 1991;13:452-8.

9. Roman MJ, Devereux RB, Kramer-Fox R, O’Loughlin J. Two-dimensional echocardiographic aortic root dimensions in normal children and adults. Am J Cardiol. 1989;64:507-12.

10. Hannuksela M, Lundqvist S, Carlberg B. Thoracic aorta: dilated or not? Scand Cardiovasc J. 2006;40:175-8.

11. Dapunt OE, Galla JD, Sadeghi AM, Lansman SL, Mezrow CK, de Asla RA, et al. The natural history of thoracic aortic aneurysms. J Thorac Cardiovasc Surg. 1994; 107:1323-33.

12. Coady MA, Rizzo JA, Hammond GL, Mandapati D, Darr U, Kopf GS, et al. What is the appropriate size criterion for resection of thoracic aortic aneurysms? J Thorac Cardiovasc Surg. 1997;113:476-91.
13. Pape LA, Tsai TT, Isselbacher EM, Oh JK, O'gara PT, Evangelista A, et al. Aortic diameter $>$ or $=5.5 \mathrm{~cm}$ is not a good predictor of type A aortic dissection: observations from the international registry of acute aortic dissection (IRAD). Cir culation. 2007;116:1120-7.

14. Rylski B, Blanke P, Beyersdorf F, Desai ND, Milewski RK, Siepe M, et al. How does the ascending aorta geometry change when it dissects? J Am Coll Cardiol. 2014;63:1311-9.

15. Paruchuri V, Salhab KF, Kuzmik G, Gubernikoff G, Fang H, Rizzo JA, et al Aortic size distribution in the general population: explaining the size paradox in aortic dissection. Cardiology. 2015;131:265-72.

16. Zafar MA, Li Y, Rizzo JA, Charilaou P, Saeyeldin A, Velasquez CA, et al. Height alone, rather than body surface area, suffices for risk estimation in ascending aortic aneurysm. J Thorac Cardiovasc Surg. 2018;155:1938-50.

17. Davies RR, Gallo A, Coady MA, Tellides G, Botta DM, Burke B, et al. Novel measurement of relative aortic size predicts rupture of thoracic aortic aneurysms. Ann Thorac Surg. 2006;81:169-77.

18. Svensson LG, Khitin L. Aortic cross-sectional area/height ratio timing of aortic surgery in asymptomatic patients with Marfan syndrome. J Thorac Cardiovasc Surg. 2002;123:360-1.

19. Svensson LG, Kim KH, Lytle BW, Cosgrove DM. Relationship of aortic crosssectional area to height ratio and the risk of aortic dissection in patients with bicuspid aortic valves. J Thorac Cardiovasc Surg. 2003;126:892-3.

20. Masri A, Kalahasti V, Svensson LG, Roselli EE, Johnston D, Hammer D, et al Aortic cross-sectional area/height ratio and outcomes in patients with a trileaflet aortic valve and a dilated aorta. Circulation. 2016;134:1724-37.

21. Krüger T, Forkavets O, Veseli K, Lausberg H, Vöhringer L, Schneider W, et al Ascending aortic elongation and the risk of dissection. Eur J Cardiothorac Surg. 2016;50:241-7.

22. Wu J, Zafar MA, Li Y, Saeyeldin A, Huang Y, Zhao R. Ascending aortic length and risk of aortic adverse events: the neglected dimension. J Am Coll Cardiol. 2019;74:1883-94.

23. Adriaans BP, Heuts S, Gerretsen S, Cheriex EC, Vos R, Natour E, et al. Aortic elongation part I: the normal aortic ageing process. Heart. 2018;104:1772-7.

24. Belvroy VM, de Beaufort HWL, van Herwaarden JA, Bismuth J, Moll FL, Trimarchi S. Tortuosity of the descending thoracic aorta: normal values by age. PLoS One. 2019;14:e0215549.

25. Chaikof EL, Blankensteijn JD, Harris PL, White GH, Zarins CK, Bernhard VM et al. Reporting standards for endovascular aortic aneurysm repair. J Vasc Surg. 2002;35:1048-60.

26. Krüger T, Sandoval Boburg R, Lescan M, Oikonomou A, Schneider W, Vöhringer L. Aortic elongation in aortic aneurysm and dissection: the Tübingen aortic pathoanatomy (TAIPAN) project. Eur J Cardiothorac Surg. 2018;54:26-33.

27. Heuts S, Adriaans BP, Gerretsen S, Natour E, Vos R, Cheriex EC, et al. Aortic elongation part II: the risk of acute type A aortic dissection. Heart. 2018;104: 1778-82.

28. Franken R, El Morabit A, de Waard V, Timmermans J, Scholte AJ, van den Berg MP, et al. Increased aortic tortuosity indicates a more severe aortic phenotype in adults with Marfan syndrome. Int J Cardiol. 2015;194:7-12.

29. Chen CK, Liang IP, Chang HT, Chen WY, Chen IM, Wu MH, et al. Impact on outcomes by measuring tortuosity with reporting standards for thoracic endovascular aortic repair. J Vasc Surg. 2014;60:937-44.

30. Parr A, Jayaratne C, Buttner P, Golledge J. Comparison of volume and diameter measurement in assessing small abdominal aortic aneurysm expansion examined using computed tomographic angiography. Eur J Radiol. 2011;79:42-7.

31. Kauffmann C, Tang A, Therasse E, Giroux MF, Elkouri S, Melanson P, et al. Measurements and detection of abdominal aortic aneurysm growth: accuracy and reproducibility of a segmentation software. Eur J Radiol. 2012;81:1688-94.

32. Trinh B, Dubin I, Rahman O, Ferreira Botelho MP, Naro N, Carr JC, et al. Aortic volumetry at contrast-enhanced magnetic resonance angiography: feasibility as a sensitive method for monitoring bicuspid aortic valve aortopathy. Invest Radiol. 2017;52:216-22.

33. Nomura Y, Sugimoto K, Gotake Y, Yamanaka K, Sakamoto T, Muradi A, et al Comparison of volumetric and diametric analysis in endovascular repair of descending thoracic aortic aneurysm. Eur J Vasc Endovasc Surg. 2015;50:53-9.

34. van Keulen JW, van Prehn J, Prokop M, Moll FL, van Herwaarden JA. Potential value of aneurysm sac volume measurements in addition to diameter measurements after endovascular aneurysm repair. $J$ Endovasc Ther. 2009;16:506-13.

Key Words: aorta, aneurysm, aortic aneurysm, aortic diameter, aortic length, aortic volume 